\title{
Closure of a recurrent giant palatal fistula with tongue flap
}

\author{
Philip Mathew $^{1}$, Manoj Kumar Bhaskaran ${ }^{2}$, Varun Menon P ${ }^{3}$, Rahul VC Tiwari ${ }^{4, *}$, Kritika Sehrawat ${ }^{5}$ \\ ${ }^{1} \mathrm{HOD},{ }^{2}$ Professor, ${ }^{3,4} \mathrm{MDS},{ }^{5} \mathrm{PG}$ Student ${ }^{1}$ Dept. of OMFS \& Dentistry, ${ }^{2}$ Dept. of OMFS, ${ }^{3}$ Dept. of FIBCSOMS, ${ }^{4}$ Dept. of FOGS, \\ OMFS \& Dentistry, ${ }^{5}$ Dept. of OMFS, ${ }^{1,3,4}$ Charles Pinto Centre for Cleft lip, Palate and Craniofacial Anomalies, JMMCH \& RI, \\ Thrissur, Kerala, ${ }^{2}$ Sree Anjenaya Institute of Dental Science, Modakallur, Atholi, Calicut, Kerala, ${ }^{5}$ Sudha Rustagi College of \\ Dental Sciences \& Research, Faridabad, Haryana, India
}

*Corresponding Author:

Email: drrahulvctiwari@gmail.com

\begin{abstract}
Introduction: Palatal fistulas can be managed conservatively or surgically depending on the size of defect. Giant fistula is usually treated with local flaps or local flaps combined with regional flaps. Tongue flaps are an excellent alternative to close wide or recurrent palatal fistulae. Here we report a case of a giant palatal fistula postcleft palate surgery which had been operated thrice and failed in different centers. This fistula has been successfully repaired in our center with posteriorly based tongue flap.
\end{abstract}

Keywords: Palatal fistula, Cleft palate, Tongue flap.

\section{Introduction}

Closure of intra-oral deformities starts with traditional approaches or local and regional flaps. Small palatal fistula results from twisted dehiscence of the mucoperiosteal folds that are utilized for palatal closure. ${ }^{1}$ Huge palatal fistula can't be closed by traditional techniques but by means of local flaps for coating and regional flaps for cover like tongue flap, temporoparietal flap, facial artery musculomucosal flap, and submental flap..$^{2-6}$ Posteriorly based buccinator myomucosal flap or radial forearm flap are likewise known for expansive palatal closure. ${ }^{7}$ Here we report an instance of a giant palatal fistula $2.5 \mathrm{~cm} \mathrm{X} 2.5 \mathrm{~cm}$ post congenital cleft palate repair which had been worked on thrice in other centers. This fistula has been repaired with local tissue for lining and a posteriorly based tongue flap for cover.

\section{Case Report}

A 4-year old child with a giant palatal fistula size $2.5 \mathrm{~cm} \mathrm{X} 2.5 \mathrm{~cm}$ post cleft palate surgery reported to our Centre for Cleft Lip, Palate and Craniofacial Anomalies with complaint of poor speech and nasal regurgitation. The parents were mortified as the child had been operated on for the same problem with local flaps at multiple centers without success. Many centers had offered the option of obturators and the closure at a later stage with temporal or temporoparietal flaps and no surgical option was offered at present. On examination, the fistula extended posteriorly from hard palate to soft palate and the width of the fistula was more than half the width of the palate (Fig. 1). Surgical closure of the fistula with combination of local tissue for lining and regional tongue flap for cover was planned.

Surgical Technique: Under general anesthesia and tracheal intubation, Xylocaine with one in two hundred thousand adrenaline was injected into the palate extensively around the lesion. A peri-fistular incision was made and the defect margins were properly de-epithelialized for the acceptance of the tongue flap. (Fig. 2) Incisions were now made at the lateral margins parallel to the gum in the mucoperiosteum to enable adequate mobilization, dissection and suturing of the nasal layer without tension. A posteriorly based tongue flap of adequate breadth was raised, rotated, and carefully inset into the defect (Fig. 3). This was the only difficult part of the procedure. Three weeks later under general anesthesia, the pedicle was divided. A small open area was found posteriorly, which was refashioned and the residual pedicle was sutured; not more than two or three sutures were required. There were no intra operative or postoperative complications. The fistula was successfully closed (Fig. 4) and the child was put to speech therapy in anticipation of some improvement of speech, the extent of which in most cases is unpredictable.

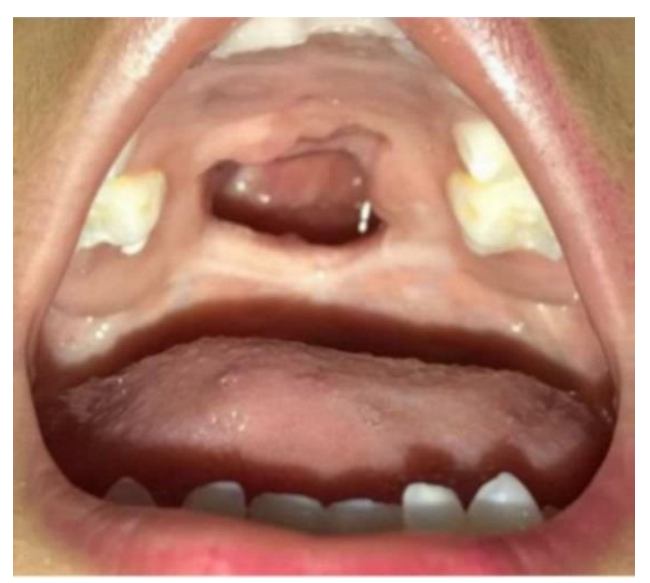

Fig. 1: A Giant palatal fistula size $2.5 \mathrm{~cm} \mathrm{X} 2.5 \mathrm{~cm}$ post cleft palate surgery 


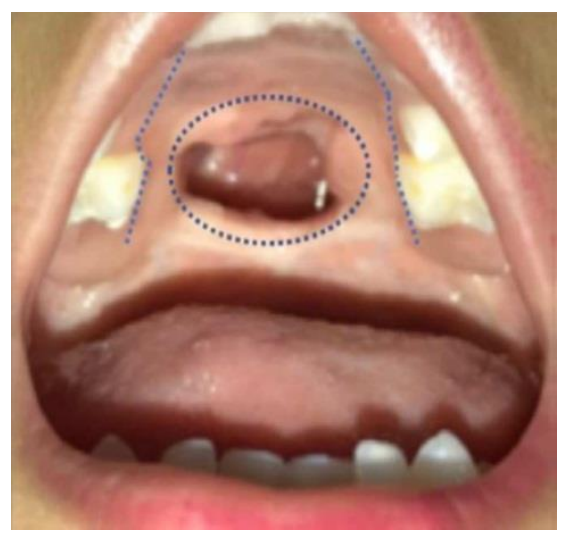

Fig. 2: A peri-fistular incision and lateral marginal incision

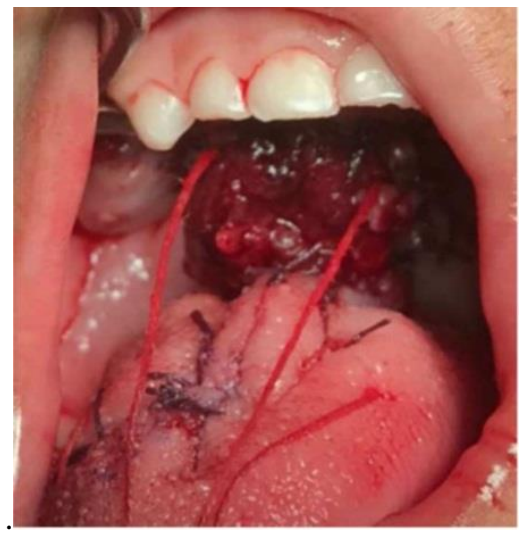

Fig. 3: Posteriorly based tongue flap of adequate breadth is raised, rotated, and carefully sutured on the defect

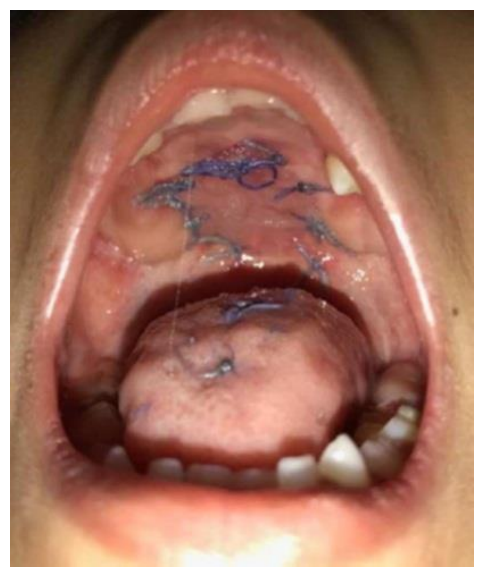

Fig. 4: Pedicle divided and most of the pedicle was repositioned into the donor site

\section{Discussion}

Tongue flaps are documented to be useful in instances of fistula repair, in palates with over abundant scarring, where the quality and amount of remaining palatal tissue does not permit basic closure, and in defects which are bigger than $1.5 \mathrm{~cm}$ width. Achievement has been accounted for with regional flaps in fistulae estimating under $1.5 \mathrm{~cm}$ widths. ${ }^{8}$ Based on defect size, Cohen ${ }^{9}$ and Posnick ${ }^{10}$ propose the following classifications: According to Posnick et al. ${ }^{10}$, Simple cleft: lesser than $1.5 \mathrm{~cm}$ in diameter, Small fistulae: Less than $1.5 \mathrm{~cm}$ diameter, Large fistulae: Larger than $1.5 \mathrm{~cm}$ diameter. According to Cohen et al. ${ }^{9}$ Small fistulae: 1 to $2 \mathrm{~mm}$, Midsize fistulae: 3 to $5 \mathrm{~mm}$. and Large fistulae: Larger than $5 \mathrm{~mm}$. Posterior based tongue flaps are advised for closure of defects on soft palate, retromolar territory and posterior oral mucosa. Anterior based tongue flaps are helpful for closure of hard palate, anterior oral mucosa, lips and floor of the mouth. Because of their vascularity, posteriorly based flaps are more secure, by the by, anterior based flaps are more adaptable because of their versatility and mobility. In this methodology, intricacies may emerge instantly, for example, bleeding, hematoma and impermanent loss of taste and transient difficulties like necrosis or dehiscence. No alterations in tongue mobility or in word articulation and enunciation have been reported; the only reported adverse sequel was a thinner and slightly scarred tongue. ${ }^{11}$ Besides that, the tongue flap on the palate does not look like palatine tissue.

\section{Conclusion}

Tongue flaps are an astounding option to close wide or intermittent palatal fistulae, since they are flexible and can be planned by size of every fistula. They are shown to be effective when different strategies have fizzled and in fistulae estimating more than $1 \mathrm{~cm}$. The brilliant vascularity exhibited in this anatomical zone guarantees achievement. Unlined tongue folds have been utilized, however the success rate is not as much as when a covering is given.

\section{Conflict of Interest: None}

\section{References}

1. Kaban LB, Pogrel MA, Perrott DH. Complications in Oral and Maxillofacial Surgery. $19971^{\text {st }}$ ed Philadelphia: W.B. Saunders Co:285.

2. Pigott RW, Rieger FW, Moodie AF. Tongue flap repair of cleft palate fistulae. Br J Plast Surg 1984;37:285-93.

3. Van der Wal KG, Mulder JW. The temporal muscle flap for closure of large palatal defects inCLP patients. Int J Oral Maxillofac Surg 1992;21:3-5.

4. Parhiscar A, Har-El G, Turk JB. Temporoparietal osteofascial flap for head and neckreconstruction. $J$ Oral Maxillofac Surg 2002;60:619-22.

5. Shetty R, Lamba S, Gupta AK. Role of facial artery musculomucosal flap in large and recurrentpalatal fistulae. Cleft Palate Craniofac J 2013;50:730-33.

6. Rahpeyma A, Khajehahmadi S, Nakhaei M. Submental artery island flap in reconstruction of hard palate after wide surgical resection of verruccous carcinoma, two case reports. Iran J Otorhinolaryngol 2013;25:177-81. 
7. Christiano JG, Dorafshar AH, Rodriguez ED Redett RJ. Repair of recurrent cleft palate with freevastus lateralis muscle flap. Cleft Palate Craniofac $J$ 2012;49:245-48.

8. Zeidman A, Lockshin A Berger J, Gold B. Repair of a chronic oronasal defect with an anterior based tongueflap: report of a case. J Oral Maxillofac Surg 1988;46:412-15

9. Posnick JC, Getz SB Jr. Surgical closure of end-stage palatal sistulas using anteriorly-baseddorsal tongue flaps. J Oral Maxillofac Surg 1987;45:907-12.

10. Buchbinder D, St-Hilaire H. Tongue flaps in maxillofacial surgery. Oral Maxillofacial Surg Clin North Am 2003;15(4):475-86.
11. Smith T, Schaberg SJ. Repair of a palatal defect using a dorsal pedicle tongue flap. J Oral Maxillofac Surg 1982;40(10):670- 73.

How to cite the article: Mathew $\mathrm{P}$, Bhaskaran MK, Varun Menon P, Tiwari R. VC, Sehrawat K. Closure of a recurrent giant palatal fistula with tongue flap. J Dent Specialities 2018;6(2):166-168. 